\title{
Physics Learning Based on Practicum: Multi-meter
}

\author{
Eka Murdani \\ STKIP Singkawang, Indonesia \\ ekamurdani@gmail.com
}

\begin{abstract}
Teaching and learning activities effectively should be able to make students active for building their knowledge by placing the teacher as a facilitator. A step to make learning effectively is to organize a practicum. By practicum, students can develop their ability to think critically, analyze, and evaluate a problem. In this practicum has been done measuring of electrical quantities such as voltage by using a multimeter and resistance of resistor by reading color of the ring (color code) and by measuring directly of the resistor's resistance by using multimeter. In this practicum students understand the use of a multimeter to measure the voltage and electrical resistance. The result of measurement for output voltage of DC power supply by using a multimeter is $3 \mathrm{~V}, 6 \mathrm{~V}, 9 \mathrm{~V}$ and $13 \mathrm{~V}$. Has been made of series and parallel circuit for 3 resistors. The resistance value of each resistor is $2000 \Omega$ same as relatively. The equivalent resistance for series circuit of 3 resistors is $6000 \Omega$ and for parallel circuit is $700 \Omega$. The equivalent resistance is measured by using multimeter and has been made also for a combination circuit of series-parallel resistor.
\end{abstract}

Keywords: Multimeter, voltage, resistance, resistor, series, parallel

\section{Introduction}

Most of our perception of the teaching is transfer knowledge actively from teacher to the students. On the other hand, perceptions of the students about learning are accept from the teacher given passively. This perception should be changed. Teaching and learning activities effectively should be able to make students active for building their knowledge by placing the teacher as a facilitator. A step to make learning effectively is to organize a practicum. By practicum, students can develop their ability to think critically, analyze, and evaluate a problem (Isliyanti \& Murdani, 2010; Murdani \& Sutarno, 2011). We often hear resistor in our life every day. Each electronic component always has a resistor. Resistor is a conductor wire. The function of the resistor is a resistance or a resistor of incoming current (Ismail, 1995; Soeharto, 1992; Soetrisno, 1979). In this paper discussed about the physics learning process based on practicum. In this learning, students are asked to solve a problem, analyze and evaluate the results of practicum about multimeter. Learning outcome of this practicum is the creation of students understanding about the use of a multimeter to measure the voltage and the electrical resistance of the resistor. In this practicum, students study some circuit of resistor such as single, series, parallel and combination series-parallel. The students make own circuit and measure directly of the equivalent resistance for each circuit.

\section{Literature Review}

Multimeter is a tool that can be used to measure some electrical quantities such as current, voltage and electrical resistance, usually it also called as AVO meter $(A=$ ampere, $V=$ volt, $\mathrm{O}=\mathrm{ohm})$. In the market there are some types of multimeter, but the principle of the guide to use it is not too much different (Ismail, 1995; Giancoli, 1998; Halliday \& Resnick, 1984). Multimeter will be used in this practicum is shown in figure 1.

Some important things to note:

a. Measuring limit: limit measure is the biggest price quantity that can be measured by the instrument. Measurements that exceed the limits of measurement can damage the appliance. Conversely, if the price scale that measured well below the limit of measurement, the measurement becomes less scrupulous. For example, we want to measure the expected voltage of $4 \mathrm{~V}$, wear limit measure $5 \mathrm{~V}$ and $50 \mathrm{~V}$. If the price is not the amount to be measured cannot be predicted, it is a safe way to start the 
measurement is to select the largest measuring limit and then lower it if it turns out that the price scale measured well below the limit of measurement used.

b. Note that the sign $(\sim)$ means AC and signs (---) indicates DC.

c. Do not connect the multimeter directly to the source of current/ voltage without series with an obstacle/ load. Direct link to the source will cause the current into the measuring instrument is large enough so that it can damage the multimeter (Ismail, 1995; Sears \& Zemansky, 1994; Tipler, 1996; Young \& Fredman, 2004).

\section{Figure 1: Multimeter}

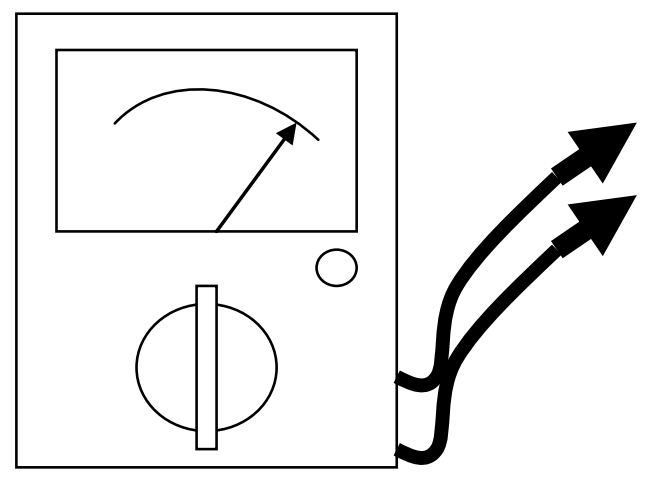

\section{Methodology}

The tools will be used in the practicum is a DC power supply, multimeter, connecting cable, resistor. The first aim of this practicum is to measure the output voltage of the DC power supply. The output voltage from strip 1 to strip 4 on the DC power supply is measured by using a multimeter. Measurement circuit is given by Figure 2.

Figure 2: The series of measurements of the output voltage on the DC power supply

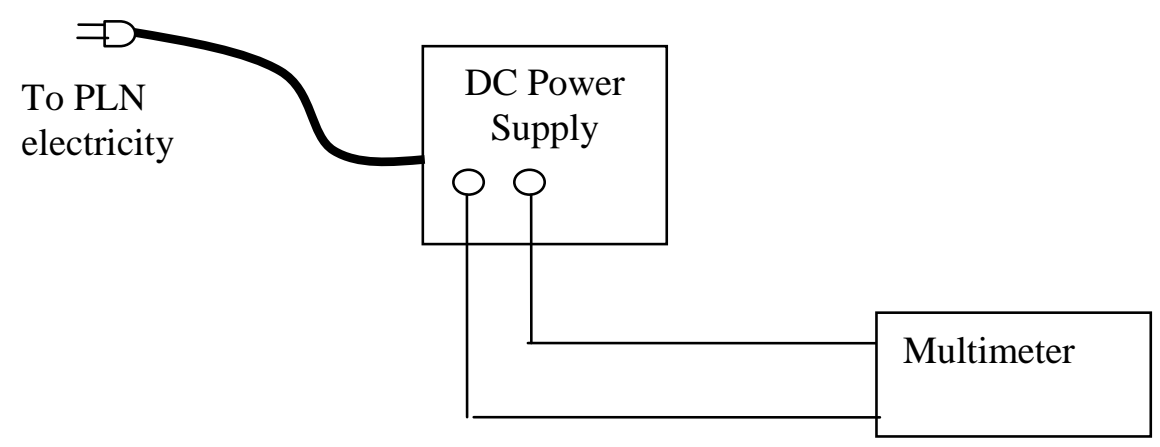

The second purpose is to measure the practical obstacles single resistor in series, series, parallel and series-parallel combination. Resistances resistor is measured by using a multimeter. Resistances resistors are also calculated based on the color of the rings resistor. 3 pieces resistor in series circuit is given by figure 3 .

Figure 3: the series of resistor series

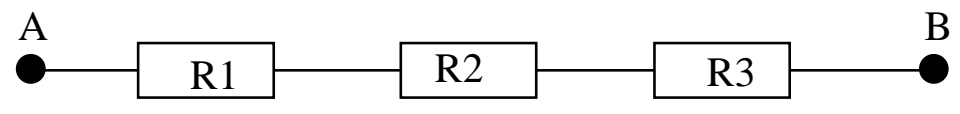

Parallel circuit for 3 resistors is given by figure 4 . 
Figure 4: Parallel circuit of resistor

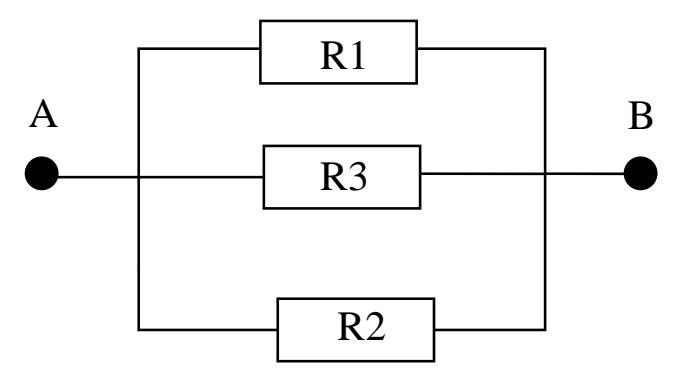

Combination circuit of series-parallel with 2 parallel resistors is given by figure 5 .

Figure 5: Combination circuit of series-parallel with 2 parallel resistors

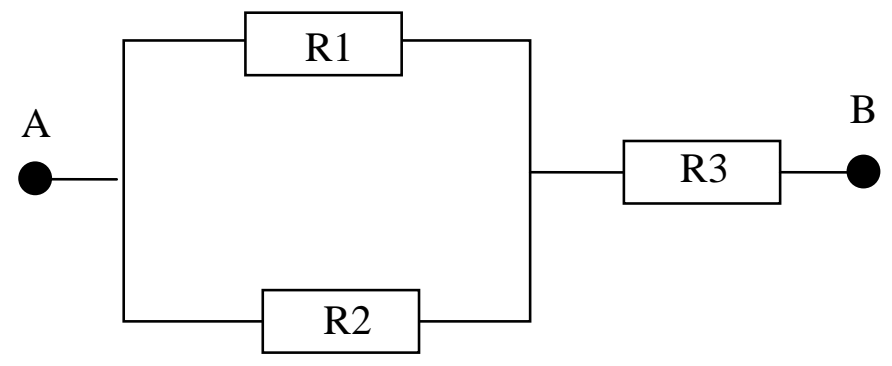

Combination circuit of series-parallel with 2 series resistors is given by figure 6 .

Figure 6: Combination circuit of series-parallel with 2 series resistors

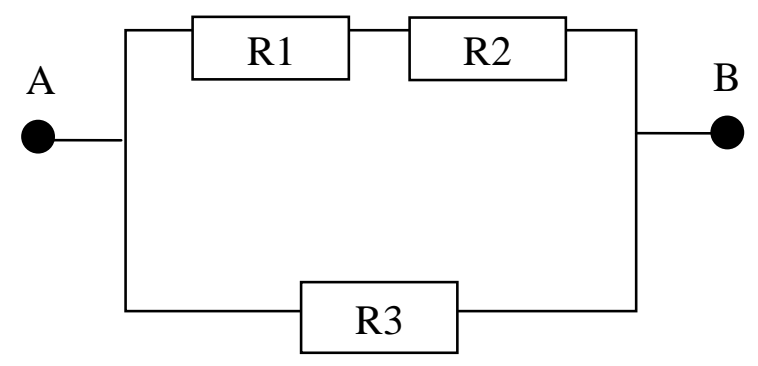

\section{Results and Discussion}

Practicum methods consist of some steps. They are preliminary tasks, pre-test, practical implementation (practicum done), interim reports and a final report. The first step is the provision of preliminary tasks. Preliminary task is given by the form of assignments or homework, with the aim is the students know in advance the basic theory that supports the practicum, along with the methodology of observation table. This preliminary task was collected before practicum begins. The basic theory associated with a multimeter and a series resistor in series and parallel. The second step is the pre-test. Pre-test is given before practicum begins in the form of a written test to see the readiness students to follow the practicum. Pre-test contains the questions about the preliminary task that has been given to the students. The third step is the practical implementation (practicum done). After the pre-test is given to the students then practicum begins. The first aim of this practicum is to measure the output voltage of the DC power supply. The output voltage for strip 1 to strip 4 on the DC power supply is measured by using a multimeter (Figure 2). The measurement results of the output voltage on DC power supply are given by table 1 . 
Table 1: The measurement results of the output voltage on DC power supply

\begin{tabular}{ll}
\hline output voltage of DC Power Supply & Multimeter measurement results (V) \\
\hline Strip 1 & $3,0 \pm 0,1$ \\
Strip 2 & $6,0 \pm 0,1$ \\
Strip 3 & $9,0 \pm 0,1$ \\
Strip 4 & $12 \pm 0,5$ \\
\hline
\end{tabular}

Based on the table 1, the greater of the power supply strip, so that the output voltage of the power supply is greater. In the DC power supply voltage can be changed as needed. The second aim of this practicum is to measure the resistance for one resistor and more resistors on series, parallel, and combination of series-parallel circuit. Resistance of resistor is measured by using a multimeter. Resistance of resistor are also calculated based on the color of the rings resistor (color code). The measurement results of resistance on a single resistor are given by Table 2 .

Table 2: The measurement results of resistance on a single resistor

\begin{tabular}{llll}
\hline Resistor & color of ring (color code) & $\begin{array}{l}\text { Resistance value based } \\
\text { on color code }(\boldsymbol{\Omega})\end{array}$ & $\begin{array}{l}\text { Resistance value based } \\
\text { on multimeter }(\boldsymbol{\Omega})\end{array}$ \\
\hline R1 & Brown, black, brown, gold & $100 \pm 5$ & $110 \pm 5$ \\
R2 & Red, black, red, gold & $2000 \pm 100$ & $2000 \pm 50$ \\
R3 & Violet, green, red, gold & $7500 \pm 375$ & $7500 \pm 250$ \\
R4 & Brown, green, red, gold & $1500 \pm 75$ & $1600 \pm 50$ \\
R5 & Brown, gray, red, gold & $1800 \pm 90$ & $1800 \pm 50$ \\
\hline
\end{tabular}

Students get experience in determining the resistance of a resistor by doing this practicum. Resistance values can be determined by reading the color of the rings resistor and can be measured directly with a multimeter. Resistance value is determined by the three color code. The fourth color code describe of precision tolerances for the resistance value. The value on the first color ring states first digit resistance. Value on the second ring color states the second digit resistance. Value on the third ring color states multiplier. So the resistance value based on the color code reading is (first ring value) (second ring value) x 10(third ring value) (Ismail, 1995; Giancoli, 1998; Halliday \& Resnick, 1984; Sears \& Zemansky, 1994; Tipler, 1996; Young \& Fredman, 2004). For example, color ring (color code) of R1 is brown, black, brown, gold, so the value of resistance is (1) (1) $\mathrm{x}$ $10^{1}=110 \Omega$ with a tolerance is $5 \%$. Tolerance of $5 \%$ means the measurement result has the truth value (measurement uncertainty) is $100 \Omega \pm 5 \%=100 \Omega \pm 5 \Omega$. Or the measurement result of resistance in the range 105 to $115 \Omega$ (Djonoputro, 1984). The measurement results of resistance on a series circuit (figure 3 ) are given by table 3 .

Table 3: The measurement results of resistance on a series circuit

\begin{tabular}{ll}
\hline Resistor & Resistances value $(\boldsymbol{\Omega})$ \\
\hline $\mathrm{R} 1$ & $2000 \pm 50$ \\
$\mathrm{R} 2$ & $2000 \pm 50$ \\
$\mathrm{R} 3$ & $2000 \pm 50$ \\
$\mathrm{R}_{\mathrm{AB}}$ & $6000 \pm 250$ \\
\hline
\end{tabular}

Students get experience in determining the resistance of the resistor series by doing this practicum. The fact on the theoretically that the equivalent resistance for 3 resistor series is sum of the each resistance $=R A B=R 1$ + R2 + R3. The equivalent resistance for series circuit will be bigger than the previous resistance or on one resistor (Ismail, 1995; Giancoli, 1998; Halliday \& Resnick, 1984; Sears \& Zemansky, 1994; Tipler, 1996; Young \& Fredman, 2004). The measurement results of resistance on a parallel circuit (figure 4) are given by table 4.

Table 4: The measurement results of resistance on a parallel circuit

\begin{tabular}{ll}
\hline Resistor & Resistances value $(\boldsymbol{\Omega})$ \\
\hline R1 & $2000 \pm 50$ \\
R2 & $2000 \pm 50$ \\
R3 & $2000 \pm 50$ \\
R $_{A B}$ & $700 \pm 25$ \\
\hline
\end{tabular}


Students get experience in determining the resistance of the resistor on parallel circuit by doing this practicum. The fact on the theoretically that the equivalent resistance for 3 resistor parallel $\left(R_{A B}\right)$ is obtained from the relation of $1 / R_{A B}=1 / R 1+1 / R 2+1 / R 3$. The equivalent resistance for parallel circuit will be smaller than the previous resistance or on one resistor (Ismail, 1995; Giancoli, 1998; Halliday \& Resnick 1984; Sears \& Zemansky, 1994; Tipler, 1996; Young \& Fredman, 2004). The measurement results of resistance on the combination of series-parallel circuit (figure 5) are given by table 5. R1 and R2 are parallelized.

Table 5: The measurement results of resistance on the combination of series-parallel circuit where R1 and $\mathbf{R} 2$ are parallelized.

\begin{tabular}{ll}
\hline Resistor & Resistances value $(\boldsymbol{\Omega})$ \\
\hline R1 & $2000 \pm 50$ \\
R2 & $2000 \pm 50$ \\
R3 & $2000 \pm 50$ \\
R $_{A B}$ & $3000 \pm 250$ \\
\hline
\end{tabular}

Students get experience in determining the resistance of the resistor on the combination of series-parallel circuit by doing this practicum. $R 1$ and $R 2$ are parallelized so that $1 / R_{P}=1 / R 1+1 / R 2$. Substitution of $R_{P}$ value to equation: $R_{A B}=R_{P}+R 3$ for determining the equivalent resistance $\left(R_{A B}\right)$ (Ismail, 1995; Giancoli, 1998; Halliday \& Resnick, 1984; Sears \& Zemansky, 1994; Tipler, 1996; Young \& Fredman, 2004). The measurement results of resistance on the combination of series-parallel circuit (figure 6) are given by table 6. R1 and R2 are in series circuit.

Table 6: The measurement results of resistance on the combination of series-parallel circuit where R1 and $R 2$ are in series circuit

\begin{tabular}{ll}
\hline Resistor & Resistances value $(\boldsymbol{\Omega})$ \\
\hline R1 & $2000 \pm 50$ \\
R2 & $2000 \pm 50$ \\
R3 & $2000 \pm 50$ \\
$\mathrm{R}_{\mathrm{AB}}$ & $1400 \pm 50$ \\
\hline
\end{tabular}

Students get experience in determining the resistance of the resistor on the combination of series-parallel circuit by doing this practicum. R1 and R2 are in series circuit so that Rs = R1 + R2. Substitution of Rs value to equation: $1 / R_{A B}=1 / R s+1 / R 3$ for determining the equivalent resistance $\left(R_{A B}\right)$ (Ismail, 1995; Giancoli, 1998; Halliday \& Resnick, 1984; Sears \& Zemansky, 1994; Tipler, 1996; Young \& Fredman, 2004). By the physics learning based on practicum will make students active, engaged directly from start to finish practice, find a direct concept, understand the concept, evoke critical thinking, able to analyze and conclude a case or concept. Students who are directly involved in the learning process will result in a longer memory capacity and more on concepts or materials provided compared with students who just quietly alone or teacher who always lecture course in the learning process. The fourth stage is the making of the interim report. After practice, the interim report prepared by the students in the form of field observation table as shown in table 1 to table 6, answer the questions and data analysis. The fifth step is the final report. The final report is complete and intact practicum collected three days after the practicum is completed. The importance of this final report is to inculcate and foster scientific writing students. So from some of the above description, it is clear that learning involves active students commonly known as the Student Centered Learning (student-centered learning/ students) will result in an effective and efficient learning. With the practicum students are trained active, being scientific, scientific thinking, analyzing scientific and scholarly writing. Which in turn will give a good image of the subjects of physics that physics is logical, sensible, scientific and not a collection of formulas (Isliyanti \& Murdani, 2010; Murdani \& Sutarno, 2011)?

\section{Conclusion}

In this practicum has been done measuring of electrical quantities such as voltage by using a multimeter and resistance by color code reading and direct measurement by using a multimeter. In this practicum students understand the use of a multimeter to measure the voltage and electrical resistance. The result of measurement for output voltage of DC power supply by using a multimeter is $3 \mathrm{~V}, 6 \mathrm{~V}, 9 \mathrm{~V}$ and $13 \mathrm{~V}$. Has been 
made of series and parallel circuit for 3 resistors. The resistance value of each resistor is $2000 \Omega$ same as relatively. The equivalent resistance for series circuit of 3 resistors is $6000 \Omega$ and for parallel circuit is $700 \Omega$. The equivalent resistance is measured by using multimeter. It has been made also for a combination circuit of series-parallel resistor. It has also produced a final report by the students as a form of scientific papers. School is a scientific institution should be able to produce students who are being scientific attitude, scientific thinking, scientific analyzing and scientific writing. By physics learning based on practicum will make students active, follow directly from start to finish practicum, find a direct concept, build critical thinking, able to analyze and conclude a case or concept. Students who are directly involved in the learning process will produce a longer memory and more capacity on concepts given learning to be effective and efficient.

Acknowledgements: Our thanks to Drs. Andi Mursidi, MPA., M.Si, the chairman of STKIP Singkawang who helped the foundation during this research and publication in $7^{\text {th }}$ International Conference on Education and Information Management, Surabaya, 2015.

\section{References}

Djonoputro, D.B. (1984). Teori Ketidakpastian Menggunakan Satuan SI. Bandung: ITB Bandung Publishing. Giancoli, D. C. (1998). Physics 2 Fifth Edition. Jakarta: Erlangga Publishing.

Halliday, D. \& Resnick, R. (1984). Physics 2 Third Edition. Jakarta: Erlangga Publishing.

Isliyanti, A. \& Murdani, E. (2010). Pembelajaran Praktikum Fisika Berbasis Penelitian: Karakteristik Kawat Pada Sekering Pengaman. Bandung: Prosiding Seminar Nasional Fisika 2010.

Ismail, B. (1995). Rangkaian Listrik Jilid 1. Bandung: ITB Bandung Publishing.

Murdani, E. \& Sutarno, D. (2011). Karakterisasi Kawat Untuk Sekering Pengaman. Bandung: Prosiding Simposium Nasional Inovasi Pembelajaran dan Sains (SNIPS) 2011.

Sears, F. W. \& Zemansky, M. W. (1994). Physics for University 2. Bina Cipta Publishing.

Soeharto. (1992). Fisika Dasar II Listrik-Magnet. Jakarta: PT Gramedia Pustaka Utama.

Soetrisno, T. I. G. (1979). Fisika Dasar: Listrik, Magnet dan Termofisika. Bandung: ITB Bandung Publishing. Tipler, P. A. (1996). Physics for Science and Technic Third Edition. Jakarta: Erlangga Publishing. Young, H. D. \& Fredman, R. A. (2004). Physics for University 2 Tenth Edition. Jakarta: Erlangga Publishing. 